\title{
11
}

\section{Indigenous data sovereignty: a Māori health perspective}

\section{Rawiri Jansen}

Nā te kune te pupuke

Nā te pupuke te hihiri

Nā te hihiri te mahara

$N \bar{a}$ te mahara te hinengaro

$N \bar{a}$ te hinengaro te manako

Ka hua te wānanga ${ }^{1}$
From the conception the increase

From the increase the thought

From the thought the remembrance

From the remembrance the consciousness

From the consciousness the desire

Knowledge becomes productive.

\section{Introduction}

I work as a health practitioner with the National Hauora Coalition (NHC), a Māori primary health care organisation (PHO) and health provider. I come to the discussion of indigenous data sovereignty as a user of data, rather than as a data practitioner. Specifically, I am interested in how we can collect, analyse and use data - mainly health data - collected over time about individual Māori and collected from groups of Māori largely with a purpose of supporting improved health outcomes for individuals, whānau (extended family) and

1 This is part of a cosmological chant recited by Te Kohuora of Rongoroa (Salmond 1991: 171-2). It situates this discussion about data, information and knowledge in a broader cosmological and cultural context. 
Māori communities. Māori engage with health providers, on average, many times a year and diagnosis, classifications, tests, investigations, treatments, prescriptions and so on will each have a data footprint. These data permit an appreciation of the experiences of the care generated-for example, which medicines are overprescribed or underprescribed to Māori, geographic variation or any unwarranted variation of prescriptions, investigations or referrals.

These sophisticated datasets and analyses are already driving evidenceled interventions for Māori primary health care. There is a need for enhanced Māori capability in the use and application of data and for more clearly specified client datasets. Māori are asserting that equity of outcomes is a fundamental element of quality in health care and an expression of our health rights. Our health data, both personally and collectively, are dispersed, distributed and disseminated. Exercising control over our data is challenging, as we need to navigate confidentiality, health privacy and commercial proprietary interests. And when we get data and convert it into intelligence and knowledge, we must use it wisely and tactically to influence the health system to deliver better outcomes.

The aim of this chapter is to explore indigenous data sovereignty from a Māori health perspective. I start, rather predictably, with a few words about rights to our data, beginning with treaty rights derived from the Treaty of Waitangi, and health and data rights derived from the United Nations Declaration on the Rights of Indigenous Peoples (UNDRIP). Then I examine a case study - or, more accurately, a set of connected case studies - that demonstrates how data can be used to inform interventions that address health and social inequalities. Specifically, I refer to a series of activities and interventions that the NHC leads to deliver improved health outcomes for Māori. These include the successful reduction of rheumatic fever in the Māori and Pacific populations of South Auckland and improved primary health care interventions across the NHC provider network. Additionally, I identify an opportunity to expand data views and data governance across the whole system rather than just data governance in one PHO. Finally, I address an issue, or an opportunity, depending on your perspective, adjacent to health data, and that is how our data can inform interventions that address inequities in the education system and may also contribute to developing a Māori health workforce that contributes to reducing health inequities. 


\section{Treaty of Waitangi}

The Treaty of Waitangi was signed on 6 February 1840 and is a useful starting point because, as Nōpera Pana-kareao asserted: 'Ko te atarau o te whenua $i$ riro $i$ a te kuini, ko te tinana o te whenua $i$ waiho ki nga Māori' ('The shadow of the land will go to the Queen [of England], but the substance of the land will remain with us'). He reversed his opinion within the year, declaring that the substance of the land had gone to the Queen and Māori retained only the shadow. Data governance, it seems, also requires thought about both the substance and the shadow of the data.

The assertion of sovereignty requires us as indigenous peoples to consider both substantive issues of data, its collection and storage and the shadow of data, its interrogation, analysis and application. Breaches of the treaty and the failure to observe the commitments therein-Māori control over lands and villages and taonga (resources) and Māori entitlement to the rights and privileges of British subjectshave led to persistent disparity across many domains of civil life, including access to and provision of services in education, health and justice and corrections.

\section{Health rights}

The right to health is contained in a broad range of international declarations, covenants and human rights instruments, from the Universal Declaration of Human Rights, the World Health Organization's constitution and the International Covenant on Economic, Social and Cultural Rights to, more recently, the UNDRIP. These human rights instruments establish the principles of equality and freedom from discrimination and also direct attention to ensuring that empowerment, participation in decision-making and accountability mechanisms contribute to the solutions and responses. Herein lies the import of data: to empower and inform the affected population, to enable our informed participation and, ultimately, to hold governments accountable.

Reid and Robson (2007: 3) assert that 'Māori have the right to monitor the Crown, and to evaluate Crown action and inaction'. They give primacy to the right of indigenous people to exercise 
self-determination, and provide a compelling critique of the health inequalities in New Zealand and the racism that underlies our current situation. They conclude with a challenge to use the data to debate fundamental questions:

[W] hat are the current and evolving health challenges facing Māori; what are the likely underlying causes; where (and how) should we intervene; what resources (human, financial and knowledge) are needed to improve Māori health outcomes and eliminate inequalities; and how should progress be monitored? (Reid \& Robson 2007: 8)

'Data is king' is a colloquialism (and, contestably, an ungrammatical one at that) that recalls a truism from financial planning ${ }^{2}$ and which I appropriate to my own purposes - that is, our ability to declaim that Māori are more likely than non-Māori to be arrested, more likely to be charged, more likely to be charged with serious offences, more likely to be found guilty, more likely to be sentenced to imprisonment (or equivalently disadvantaged at every step of the cancer journey or any number of other journeys through the health, housing, education, justice or corrections systems). Access to data - and especially access to our data - and our ability to analyse those data give us the resources to deconstruct such institutionalised racism. Indeed, our critical understanding is predicated on access to real, reliable, accurate data and robust analysis. Thus informed and resourced, we can resist and defy or reclaim and occupy - exercising a full range of responses in our struggle for equity.

\section{The role of data in reducing inequities: examples and possibilities}

\section{Rheumatic fever}

High rates of rheumatic fever, cellulitis and other preventable conditions affect Māori, Pacific and low socioeconomic populations in South Auckland (Wilson 2010; Vogel et al. 2013). This has significant costs to the individual, to families and communities and to the district

2 Of uncertain provenance and sometimes asserted as 'cash flow is king', it is a strident reminder to the business owner to pay close attention to managing income and expenditure (Lant 1991:48-56; Bremner 1995:37; The Economist 1995:80). 
health board (DHB) and wider society. Research by Carapetis et al. (2005) shows that the median incidence of acute rheumatic fever (ARF) is more than three times higher among Pacific and indigenous populations in Australia and New Zealand than in any other region in the world (Figure 11.1).

The influential work of Jackson and Lennon (2011) on rheumatic fever in New Zealand from 1998 to 2010 showed that rheumatic fever rates vary by age, by ethnicity, by geography (in a north-south gradient) and by deprivation. Māori children have rates that are 47 times higher and Pacific children 69 times higher than non-Māori and non-Pacific children. Children living in the most socioeconomically deprived areas in the Auckland region (decile 9-10) have a 36 times higher rate of contracting rheumatic fever than children living in the least deprived areas (decile 1-2). The highest rates of ARF also occur in school years one to eight (ages 5-14), where the school has a low decile $(1-2)^{3}$ and high Māori or Pacific enrolment (Jackson \& Lennon 2011).

There is also a strong link between household crowding and rheumatic fever (Jaine et al. 2011). Living in crowded housing conditions increases the transmission rates of a range of infectious conditions including Group A Streptococcal (GAS) throat infections. Structural crowding and functional overcrowding both contribute to rheumatic fever risk. Information from the 2006 census demonstrates the prevalence of structural household crowding ( $1+$ bedroom deficit) is higher among the Māori (23 per cent) and Pacific (43 per cent) populations (Baker et al. 2012). In the Auckland metro area, the levels of crowding are higher than national levels, particularly for Pacific children and youth (Craig et al. 2012: 93).

Rheumatic fever prevention strategies were needed at three levels:

- Addressing social determinants of health, including interventions that address household crowding and raising community awareness.

- Improving access to primary care to treat GAS-positive sore throats, including school-based clinics to treat sore throats and health promotion messages and activities.

3 The areas of greatest socioeconomic disadvantage are those at the high end of the spatial deprivation scale (9-10). In contrast, the most deprived schools are those at the low end of the school decile ranking $(1-2)$. 
- Secondary prevention activities through the active provision of prophylactic antibiotics to reduce recurrent cases and rheumatic heart disease.

To address these prevention strategies, the NHC led the development of a comprehensive program that included 'Mana Kidz', a nurseled school-based health service that has now been established in 61 primary and intermediate schools in South Auckland; 'Rapid Response' sore throat clinics in 16 secondary schools and 30 primary care clinics; and the Auckland Wide Healthy Homes Initiative (AWHI) to improve housing conditions (see AWHI 2014).

\section{Rheumatic fever prevention: Mana Kidz}

The NHC was awarded a Ministry of Health contract in 2012 to provide a nurse-led school-based rheumatic fever prevention program, Mana Kidz, which aimed to improve access to primary care, treat GASpositive sore throats and skin infections and provide a comprehensive school health service. The design stages of the program were evidence informed by the work of the public health physicians at the Auckland Regional Public Health Service and the district health boards alongside clinical leadership from paediatricians.

Spatial analysis of cases by school location was critical for the design of the program that was funded by the Ministry of Health and the Counties Manukau District Health Board (see Counties Manukau District Health Board 2013). This analysis informed the deployment of a school-based comprehensive health service in 61 schools across the South Auckland region where Māori children are concentrated. Similar analysis either is not available in other districts or, where it is, does not indicate sufficient rate density distributed by school to warrant the deployment and investment required to support the school-based service model.

Critical contributions to the design and deployment of a program such as Mana Kidz have been the data collection, analysis and measures reporting. Through Mana Kidz, more than 25,000 children and whannau now have daily access to health services addressing skin infections and sore throat assessment and management. As of March 2015, 98 per cent of eligible children were given consent to join the program, over 21,000 GAS-positive sore throats were treated and a further 19,510 skin infections were treated (the majority through cleaning and covering and a smaller number with antibiotics). 
Participation and progress are monitored via a regularly updated Mana Kidz scorecard (Figure 11.1), which ensures that children and whānau who test positive for GAS receive speedy treatment and that eligible families are referred to the AWHI for housing solutions to reduce the likelihood of developing rheumatic fever.

\section{MANA KIDZ: PROGRESS AND OUTCOMES}

MARCH 2015

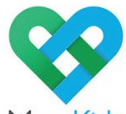

ManaKidz

Contributing to all children having the best start in life

What we do: Mana Kidz is a nurse-led, school-based health programme providing free throat and skin assessment, treatment and follow-up, plus other child health services and referrals, in 61 schools across South Auckland. Mana Kidz offers an inter-disciplinary school team approach to health and wellbeing for children and their whānau.

Who we serve: The 24,942 children attending 61 schools in Otara, Mangere, Manurewa, and Papakura
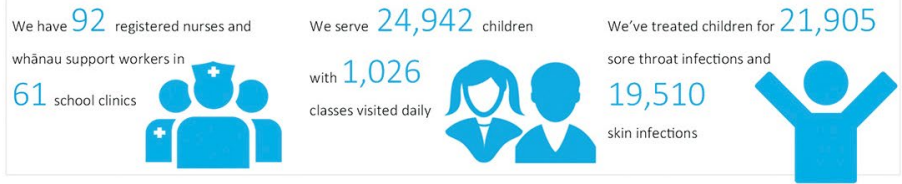

Health outcomes:
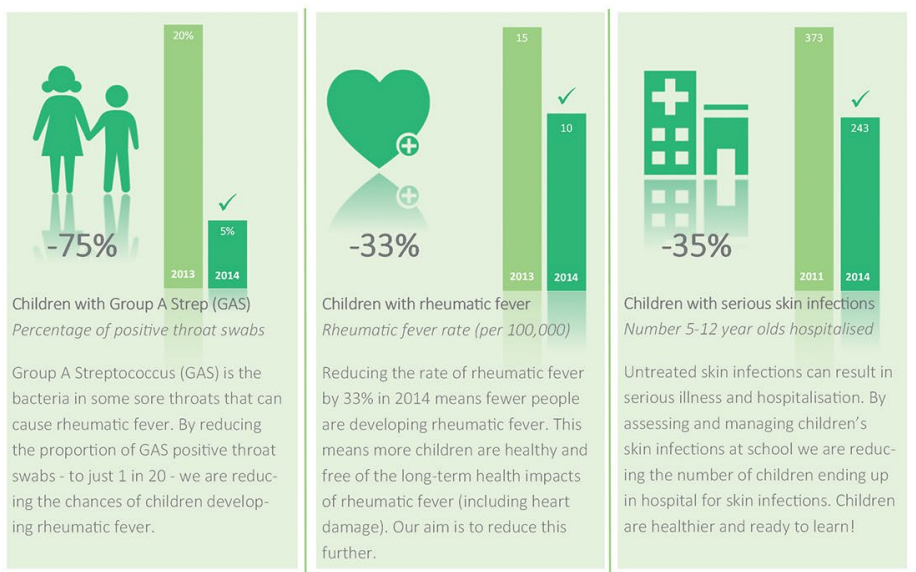

Things we are doing to improve

1. Undertaking quality improvement projects to ensure that children and whanau who test positive for Group A Streptococcus receive free treatment as quickly as possible.

2. Ensuring that eligible families are referred to the Auckland Wide Housing Initiative (AWHI) and Warm-Up for housing solutions in order to reduce likelihood of developing Rheumatic fever.

3. Work closely with schools and community groups to promote good skin hygiene among whänau

Figure 11.1 Mana Kidz data scorecard

Source: National Hauora Coalition, Auckland. 


\section{Rheumatic fever prevention: rapid response clinics}

'Rapid Response (Sore Throat Management in Secondary Schools and Primary Care Clinics)' services more than 65,000 4-19-year-olds at high risk of rheumatic fever and provides free access to assessment and treatment of sore throats.

Similar to Mana Kidz, here data collection and analysis have informed the deployment and distribution of free primary care clinics delivering rapid response, nurse-led sore throat assessment and treatment clinics. The NHC developed and deployed the electronic forms to capture the activity in the rapid response clinics. This includes demographic data (age, gender, ethnicity, geocoded domicile, school attended) and clinical data (sore throat as the presenting complaint, weight, clinical signs including temperature and clinical assessment of the patient's throat, symptomatology including cough, prescription and medication supply). Related activity data are also collected including date and time of visits and laboratory data including lab request forms and lab results. Analysis of these linked data provides the project team with a rich picture and allows it to assess whether patient cohorts receiving the service align with the program's intention (by age, ethnicity and quintile). ${ }^{4}$ The NHC regularly transmits these data to our provider clinics and funders as a scorecard. We also conduct analyses to inform us of the quality of the clinical services (tested against the National Heart Foundation Sore Throat Management Guideline) and the program quality (for instance, the number of clinical attendances completed by practitioner type or attendances versus funding).

In these ways, the collection of data across this network of 61 primary and secondary schools and 30 primary care clinics informs the ongoing management of the rheumatic fever prevention program. It allows the program governance group to drive performance, to strengthen the investment or to disinvest decisively.

4 The NZDep2006 index of socioeconomic deprivation uses a reduced five-point scale (quintiles), each of which collapses two deciles. That is, NZDep2006 values 9 and 10 are combined as quintile 5, which indicates the most deprived 20 per cent of the population for small areas (meshblocks or census area units) (White et al. 2008). 


\section{Rheumatic fever prevention: the AWHI}

The NHC, with our partner, the OLA Coalition Limited, ${ }^{5}$ has designed and established a regional housing hub that works with families who have a high risk of rheumatic fever. Our role is to connect people to local services and organisations that can help them to create healthy homes. We help families to develop their own housing plans and to increase housing literacy. At the heart of our approach is the recognition that supporting our families also means ensuring they have the skills to make better choices in the future in ways that are meaningful to them.

The eligibility criteria are very specific: children must have had a specific diagnosis from an admission to one of three Auckland hospitals ${ }^{6}$ or three confirmed GAS throat infections in a three-month period, and the families must have income below set thresholds and have household crowding and more than one child in the household. The complexities should be obvious: the intention to provide a coordinated, customised and targeted service intervention for an eligible population through a complex intersection of clinical events and investigations, with income, housing and household membership characteristics. Construction of these datasets has been challengingin terms of access to the data and in terms of concordance across datasets. This has led to a significant reduction in the numbers of families identified to receive the service interventions, from 3,000 per year to 1,600 per year.

The service interventions need to align with housing outcomes for families: measurable and reliable changes in circumstances for families to have warm, dry, safe homes. Overcrowding will have predictable drivers, including the obvious financial benefit from families sharing the costs of rent, power or food, and other cultural benefits of being connected with a wider family network, supportive interrelationships and alignment with traditional family customs. A housing literacy approach asserts that families are entitled to know and understand the risks and benefits of their living arrangements and make reasonable and rational decisions to manage those risks and maximise the benefits. The service interventions include insulation, heating, beds and

5 The OLA Coalition Limited is a joint-venture limited liability company 50 per cent owned by the NHC and 50 per cent owned by AllianceHealth Plus, an Auckland-based Pacific PHO.

6 www.starship.org.nz/media/259329/starship_30_july_nc_.pdf. 
bedding and minor repairs (all of which address functional rather than structural overcrowding), housing entitlements and income assessments and Housing NZ fast-tracking (which addresses structural overcrowding). ${ }^{7}$

Noting the complex development issues in building the service delivery model, the program is now demonstrating outcomes for families. The data challenges in this include coordination across a network of eight nongovernmental organisation (NGO) providers and five major suppliers while neither suppliers nor providers share a single information technology (IT) platform. Nonetheless, a successful monitoring and reporting scorecard platform has been established, showing eligible referrals received by referral source, housing assessments undertaken and housing plans implemented according to housing outcomes (income, insulation, minor repairs, and so on)-all classifiable by Māori, Pacific and other ethnic status (Figure 11.2).

It is clear that data privacy complexities must be managed. Should the referring hospital service be entitled to know the result of the income benefit assessment or just that such an assessment was undertaken? A family living in an overcrowded house may decline to have the insulation provider involved because that may alert the landlord to, for example, overcrowding, which would represent a breach of the tenancy agreement and potentially lead to termination of tenancy. Again, control and use of the data have predictable risks and benefits, at an individual as well as a collective level.

The scorecards for the AWHI can quickly and effectively demonstrate data that show the number of families and their progress in the journey from referral through to interventions, and to follow-up months later. We use the scorecard to provide visibility of reliable, accurate data. For our provider network, this supports them to deliver high performance in terms of timeliness and quality. For referrers and funders, this supports them in knowing that the referred families are receiving interventions that are appropriate. Finally, and most importantly, whānau and communities need to see that the AWHI is delivering the appropriate interventions in a timely way and that

7 See the Housing New Zealand website: hnzc.co.nz/news/older-news-items/september-2013/ rheumatic-fever-sas. 
the interventions deliver durable changes in circumstances to the vulnerable families that we serve. Data - specifically our data (that is, data about us) - accessed and controlled by us, help us drive performance and deliver outcomes.

\section{PROGRESS AND OUTCOMES}

1 July 2014- 24 June 2015

福住awhi

AWHI (Auckland Wide Housing Initiative) has a key focus to reduce crowding in families with children at high risk of Rheumatic Fever. At the heart of the approach is the recognition that supporting families also means ensuring they have the skills to make better choices in the future. The role of AWHI is to be the connector of services and solutions. We are building a platform for collaboration and collective impact.

Our partners are National Hauora Coalition, Alliance Health Plus, Health Star Pacific, Health West, Penina Health Trust, South Seas, Te Hononga o Tamaki me Hoturoa, Tongan Health Society, Toa Pacific and Turuki Health Care.

AWHI client pathway I 1 Jul $2014-24$ June 2015

Eligible referrals
received
1029
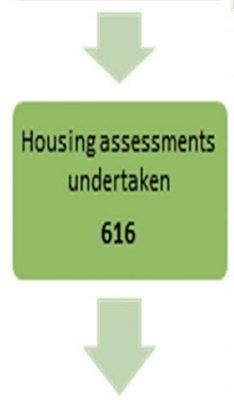

Housing plans implemented

580
DHB \& referral source |1 Jul 2014 -24 June 2015

\begin{tabular}{|c|c|c|}
\hline ADHB & CMDHB & WDHB \\
\hline Bicillin Service & Bicillin Service & Bicillin Service \\
\hline 31 & 200 & 24 \\
\hline Hospital & Hospital & Hospital \\
\hline 129 & 387 & 47 \\
\hline $\begin{array}{l}\text { School-based throat } \\
\text { swabbing }\end{array}$ & $\begin{array}{l}\text { School-based } \\
\text { throat swabbing }\end{array}$ & $\begin{array}{l}\text { School-based } \\
\text { throat swabbing }\end{array}$ \\
\hline 22 & 180 & 9 \\
\hline
\end{tabular}

Housing outcomes | 1 Jul 2014-24 June 2015
Ethnicity |1 Jul 2014-24 June 2015

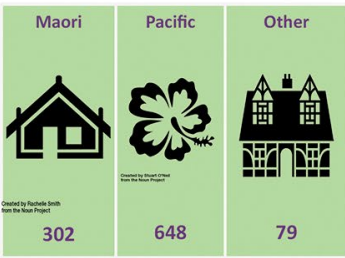

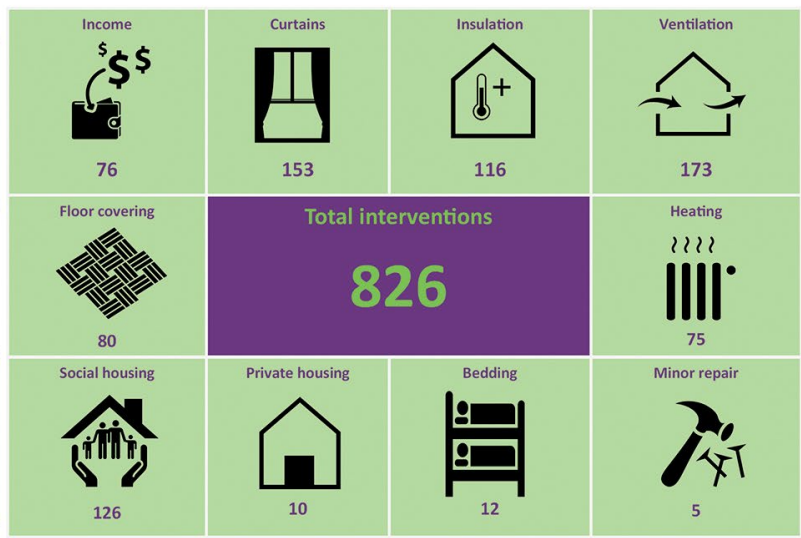

What we need to improve:

1. Increase the supply of interventions, in order to deliver AWHI services to all families more efficiently.

2. Generate an increased number of referrals by ensuring that all identified children who meet AWHI eligibility are referred into the AWHI Hub within an appropriate timeframe.

3. Ensuring our system is as responsive as possible to meet the urgent needs of whannau for warm, dry and uncrowded housing. This requires engagement with families in a timely manner and working closely with all stakeholders to improve health outcomes for whānau.

\section{Figure 11.2 The AWHI data scorecard}

Source: National Hauora Coalition, Auckland. 


\section{Cardiovascular disease}

The NHC, as a PHO, has some 35 primary care clinics with 135,000 enrolled patients. Managing our data has been useful in focusing our provider network to deliver to our Māori enrolled population. Specifically, the NHC accesses and controls these data directly from our provider network; they are not mediated through a Crown agent or other intermediary.

Māori have a disproportionately higher rate of cardiovascular disease (CVD) than the rest of the population and a significant inequity of appropriate screening and management. CVD risk assessment is a national health target (NHT), and performance against this generates an incentive payment to the NHC (which is passed through to the provider network). Through the application of our own discretionary funding pool, the NHC provides incentives for the management of Māori with a CVD risk of 15 per cent or greater. This arrangement supports providers to undertake the CVD risk screening (contributing to their NHT performance and incentive payment) and then access CVD management funding. The rationale is that management (and not screening) is the driver of improved CVD outcomes. Real-time decision support is provided and real-time data are collected.

To facilitate this, Mōhio Forms (the NHC IT platform used nationally across the NHC provider network) delivers electronic claim forms with budget control, a dashboard with program and contact information, real-time data collection and reporting. Mōhio is available via the internet or within the patient management system where electronic forms are auto-populated. Data are validated as they are entered and claims are invoiced and budgets allocated in real time. When users submit the form, a receipt is provided and relevant health, process or claims data are written back to the patient management system. Mōhio Forms provides a rich data picture of the activity of our provider network in real time that allows us to drive performance and tailor direct and responsive feedback to the NHC provider network.

As with the Mana Kidz and AIHW platforms, the Mōhio dashboard visually presents data on the performance of individual health targets and can be disaggregated by ethnicity and detailed geography. It also displays the results of individual providers or by district or in aggregate across the NHC network. This output will be further 
developed to show performance by relative rate ratios (comparing the rates at which a health target is achieved by the provider for the Māori and non-Māori populations) as a measure of equity performance.

Once again, access, control and, in this case, ownership of our data are informing and resourcing us to identify rational responses to health inequities and to drive performance. Based on analysis of our health data, the NHC is able to deploy a tactical funding response to improving the service delivery of our provider network and is lifting performance in strategic interventions (such as CVD risk management, immunisations and cervical screening). ${ }^{8}$

\section{Expanding access to primary care data: data-sharing protocols}

In the previous section, I discussed some opportunities for using data over which we currently exercise control or access to inform our activities and interventions. The immediately adjacent space is to consider similar data that are held and controlled by other organisations active in primary care. This includes other PHOs and also Crown entities such as DHBs.

PHOs and DHBs have overlapping service delivery and accountability for health service planning. In Auckland, there are three DHBs and seven PHOs serving a population of over 1.3 million. Sharing data to inform health service planning, delivery and performance underpins a rational collaboration. ${ }^{9}$ The Metro Auckland Data Stewardship Group (MADSG) has been formed to navigate the issues of health information use, management and privacy across the health system. A purpose-use matrix has been developed to provide the guidelines to support the need to share information to support the whole-of-system approach while maintaining patient privacy and professional confidentiality requirements. ${ }^{10}$ PHOs and DHBs have jointly agreed to the following purposes as the basis of the purpose-use matrix:

8 For a detailed discussion on which interventions are likely to contribute to improved health outcomes or life expectancy (and why), please see Robson and Harris (2007).

9 Shared Health Information Privacy Framework Version 10, 20 June 2013. For a recent discussion of electronic shared care records, see: www.privacy.org.nz/assets/Files/Reports-toParlGovt/Electronic-Shared-Care-Records-Elements-of-Trust-report-1.pdf.

10 See Auckland District Health Board (2015). 
- direct patient care

- clinical audit

- service management, monitoring and resource allocation

- planning and service development

- research.

The NHC is committed to improving health outcomes for Māori and other underserved populations, whether or not they are our enrolled patients. The data-sharing agreement suggests that a basis for examining data across the whole system is now possible and it is consistent with the overarching principles of quality and equity. For example, examining general practitioner (GP) utilisation data for patients seen in hospital emergency departments might uncover enrolment practices that disadvantage Māori. Examination of GP utilisation data and pharmaceutical prescribing and dispensing data may identify specific cohorts of patients who are underserved in CVD risk management or diabetes management or overprescribed renotoxic medications for gout, and so on. The data are likely available and amenable to an equity analysis right now, but access to the data is currently proprietary - they are owned and held by autonomous and sometimes commercial health provider organisations. The governance organisations have agreed that the data-sharing protocols will enable the establishment of a Māori data-sharing governance framework. An indigenous data sovereignty framework such as this can provide opportunities for an equity analysis and, informed by such an analysis, we can resource appropriate interventions to deliver improved health equity.

\section{Intersectoral data to deliver health equity: the education system and Māori doctors}

Associated with the push for greater access to and control of our health data for use in addressing health inequities are the intersections that exist between health equity and the education system. I have been a member of Te Ohu Rata o Aotearoa (Māori Medical Practitioners Association) since I was a medical student and currently (and recurrently) serve on the board. To generate more Māori doctors, we need to examine the education journey for Māori, including the 
upstream delivery: the secondary school system. Unfortunately, many Māori students attend secondary schools that do not teach science to the National Certificate of Educational Achievement Level 3. And for those who do achieve that standard, we recruit many of them-and, questionably, too many of them - into medical undergraduate courses. Tactically, we should perhaps be trying to grow both Māori secondary science teachers and Māori doctors.

Further downstream, however, Aotearoa/New Zealand has achieved a remarkable feat: ${ }^{11}$ to my knowledge, it is the only jurisdiction in the world to have achieved equitable per capita representation of indigenous students in medical undergraduate entry. Currently, some 15 per cent of the medical school intake into both Auckland and Otago schools of medicine are Māori, and it is reasonably expected that this proportion will continue.

Similarly, the Royal New Zealand College of General Practitioners (RNZCGP) is, to my knowledge, the first medical vocational college in any jurisdiction to establish an indigenous faculty (RNZCGP 2016). The Māori faculty of the RNZCGP is named after the first Māori doctor, the late Sir Maui Pomare, who graduated in 1899 from the Adventist Medical College in Chicago. Te Akoranga a Maui (the Māori faculty) has more than 100 Māori GPs networking throughout Aotearoa/New Zealand - predictably, involved in all aspects of recruiting, supporting and mentoring Māori doctors through their vocational training and in community health care settings.

Additionally, Māori GPs exert their influence across all aspects of the college's business, seeking to give a Māori voice and a Māori perspective to the curriculum and to the college's structures and leadership. One area of interest is accessing and using the data that the college collects about Māori patients through its activities. For instance, applicants for college fellowships are required to collect experience-of-care data from a sample of patients. ${ }^{12}$ The patient questionnaire data collected from Māori patients might be analysed across all applicants or over time to illuminate some aspects of care provision for Māori. Similarly, the patient questionnaires that form part of the cornerstone accreditation

11 All credit to the two medical schools and their impressive Māori women leaders, Professor Papaarangi Reid and Associate Professor Joanne Baxter, who have resourced this achievement. 12 Better Practice Patient Questionnaire, see RNZCGP (2011: 19). The RNZCGP Better Practice Patient Questionnaire is available from the college in Māori, Samoan, Chinese and Korean. 
process (by clinic provider, rather than by practitioner) should also yield some interesting information when disaggregated by ethnicity. Te Akoranga a Maui is currently asserting a Māori data governance role in those datasets. Access and control of Māori data held by the RNZCGP could inform training programs for GPs and GP registrars. Improving GP training programs can contribute to better primary care service delivery and to primary health care services that focus on delivering interventions to reduce inequities.

\section{Conclusion}

In this chapter, I have used examples from the health sector to discuss how indigenous data sovereignty in Aotearoa/New Zealand can contribute to Māori health outcomes and to health equity. The assertion that data sovereignty comes from our right to our data can be sourced from the Treaty of Waitangi and from the UNDRIP, to which Aotearoa/New Zealand is a signatory. For myself, working as a Māori health practitioner, in a Māori-led, kaupapa-driven organisation, ${ }^{13}$ I assert that Māori sovereignty is informed by knowing about ourselves. Knowing who we are, where we are, what we do, when we do it, how we do it or how much we do what we do-all of the data that describe who we are are our data, and are likely to be useful and informative and amenable to our analysis.

Robson and Reid (2001) promoted the idea 15 years ago that data produced by the Crown should be at least as effective for Māori as for non-Māori. With other Māori health colleagues, they also argued persuasively that health surveys should be constructed consistent with the principle of 'equal explanatory power' (Te Roppu Rangahau Hauora a Eru Pomare 2002). Those seminal papers have been hugely influential in the design of official surveys and have contributed to ensuring Māori data visibility. Data visibility has been a useful tool in monitoring the Crown (again, Robson \& Reid 2001) and is especially relevant when considering official data. The next development - one that I think becomes explicit in the examples from this chapteris data accessibility. The datasets that inform Mana Kidz sometimes sit in official sources (government ministries, DHBs and schools), but they

13 Kaupapa Māori health provision is based on a set of distinctively Māori principles and values. See, for example: rangahau.co.nz/research-idea/27/. 
also sit in adjacent entities (private companies, commercial entities, PHOs and NGOs) that are funded by the Crown through the Ministry of Health or DHBs. It seems that we move up a hierarchy from data visibility and data accessibility to data sharing and data control. These are forms of data governance that, consistent with indigenous data sovereignty, can inform and resource Māori to influence, monitor and hold the health system to account for Māori health outcomes and for equity. Data sovereignty is more than holding the health system or the Crown to account. Māori sovereignty is informed by Māori data sovereignty.

\section{References}

Auckland District Health Board (2015). Metro Auckland data sharing guideline, application of the information purpose-use matrix, Auckland District Health Board, Auckland.

Auckland District Health Board (2014). AWHI (Auckland Wide Healthy Homes Initiative) documentation, Auckland District Health Board, Auckland.

Baker MG, Goodyear R, Telfar-Barnard L \& Howden-Chapman P (2012). The distribution of household crowding in New Zealand: an analysis based on 1991 to 2006 census data, He Kainga Oranga/Housing and Health Research Programme, University of Otago, Wellington.

Bremner B (1995). Cash is king for corporate Japan. Business Week, 1 May 1995, bloomberg.com/news/articles/1995-04-30/cash-is-kingfor-corporate-japan.

Carapetis JR, Steer AC, Mulholland EK \& Weber M (2005). The global burden of group A streptococcal diseases. Lancet Infectious Diseases 5(11)(November):685-94.

Counties Manukau District Health Board (2013). Shared health information privacy framework, Ministry of Health, Auckland.

Craig E, Dell M, Reddington A, Adams J, Oben G, Wicken A \& Simpson J (2012). The determinants of health for children and young people in New Zealand, Ministry of Health, Wellington. 
Jackson C \& Lennon D (2011). Rheumatic fever in the Auckland regions 1998-2010: data from the rheumatic fever register, Paediatric Infectious Diseases, Starship Children's Health \& Auckland Regional Public Health Service, Auckland District Health Board, Auckland.

Jaine R, Baker M \& Venugopal K (2011). Acute rheumatic fever associated with household crowding in a developed country. Paediatric Infectious Diseases 30(4)(April):315-19.

Lant J (1991). Cash is king. Small Business Reports.

Reid P \& Robson B (2007). Understanding health inequities. In Robson R \& Harris R (eds), Hauora: Māori standards of health. IV: a study of the years 2000-2005, Te Rōpū Rangahau Hauora a Eru Pōmare, Wellington.

Robson B \& Reid, P (2001). Ethnicity matters, Statistics New Zealand, Wellington.

Robson R \& Harris R (eds) (2007). Hauora: Māori standards of health. IV: a study of the years 2000-2005, Te Rōpū Rangahau Hauora a Eru Pōmare, Wellington.

Royal New Zealand College of General Practitioners (RNZCGP) (2011). Aiming for excellence, RNZCGP standard for NZ general practice, RNZCGP, Wellington.

Royal New Zealand College of General Practitioners (RNZCGP) (2016). Faculties \& chapters, RNZCGP, Wellington, oldgpl6.rnzcgp.org.nz/ assets/documents/News--Events/WEBRGP-8115-Maori-strategy.pdf.

Salmond A (1991). Two worlds: first meetings between Māori and Europeans, 1642-1772, Viking, Auckland.

Te Rōpū Rangahau Hauora a Eru Pomare (2002). Mana whamamārama: equal explanatory power-Māori and non-Māori sample size in national health surveys, Ministry of Health, Wellington.

The Economist (1995). Where cash flow is king. The Economist, 18 February 1995. 
Vogel AM, Lennon DR, Gray S, Farrell E \& Anderson P (2013). Registered nurse assessment and treatment of skin sepsis in New Zealand schools: the development of protocols. New Zealand Medical Journal 126(1380):27-38.

White P, Gunston J, Salmond C, Atkinson J \& Crampton P (2008). Atlas of socioeconomic deprivation in New Zealand, NZDep2006, Ministry of Health, Wellington.

Wilson N (2010). Rheumatic heart disease in indigenous populations: New Zealand experience. Heart, Lung and Circulation 19(5-6):282-8. 
This text is taken from Indigenous Data Sovereignty: Toward an agenda, edited by Tahu Kukutai and John Taylor, published 2016 by ANU Press, The Australian National University, Canberra, Australia. 